\section{Carambola Growth and Leaf Gas- exchange Responses to Seismic or Wind Stress}

\author{
Thomas E. Marler ${ }^{1}$ and Yasmina Zozor \\ Fairchild Tropical Garden, 11935 Old Cutler Road, Miami, FL 33156
}

Additional index words. Averrhoa carambola, mechanical stress, photosynthesis

\begin{abstract}
Growth and leaf gas-exchange responses of carambola (Averrhoa carambola L.) seedlings to wind or seismic stress were studied under glasshouse conditions. Forty days of twice daily seismic stress applied for 10 seconds consistently reduced carambola height, leaf area, dry weight, relative growth rate, and leaf-area ratio, but increased trunk cross-sectional area compared with plants receiving no seismic stress. Fifty-one days of wind load reduced plant height, leaf area, dry weight, trunk cross-sectional area, net assimilation rate, relative growth rate, leaf-area ratio, and stomatal conductance compared with plants receiving no wind stress. Morphological appearance was similar for plants receiving wind or seismic stress. Net $\mathrm{CO}_{2}$ assimilation of carambola leaflets was reduced by 30 minutes of wind load for up to 6 hours following the stress. Results suggest that wind may reduce carambola growth at least partially by influencing leaf gas exchange or by the mechanical stress associated with wind.
\end{abstract}

Physical disturbances such as wind, shaking, or touching influence plant growth, development, and physiology in many ways (Biddington, 1986). Wind is a common cause of mechanical stress in plants, however, the proportion of wind-induced plant growth reduction that can be attributed to mechanical stimulation is not known (Grace, 1977; Jaffe, 1980; Neel and Harris, 1971).

Carambola is highly sensitive to wind stress, but little is known about wind effects on its growth and development. Growers in southern Florida construct synthetic wind breaks around fields, finding this practice economically feasible due to the sensitivity of this species. The objectives in this series of glasshouse studies were to determine and compare carambola plant responses to wind and seismic stress under the same conditions, and measure the aftereffects of wind stress on carambola photosynthesis.

Plants were grown on raised benches under glasshouse conditions (50\% whitewash shade) before and during the experiment periods. The container medium was equal parts by volume of shredded pine bark, silica sand, perlite, and peat. 'Golden Star' carambola seeds were planted in 3.1-liter clay containers on 8 May 1990, and single seedlings were transplanted into 2.6-liter containers on 28 June. Plants were watered by hand daily to pot capacity. A top dressing of $5 \mathrm{~g} 12 \mathrm{~N}$ 2.6P-6.6K-2.4Mg-1.5Mn-0.1Cu-0.1Zn$1.3 \mathrm{Fe}$ granular fertilizer and a $125-\mathrm{ml}$ drench of $2.5 \mathrm{mM} \mathrm{Fe}$ (as Fe-EDDHA) solution was applied to each container every 8 weeks.

Received for publication 25 Oct. 1991. Accepted for publication 27 Apr. 1992. The cost of publishing this paper was defrayed in part by the payment of page charges. Under postal regulations, this paper therefore must be hereby marked $a d$ vertisement solely to indicate this fact.

'Current address: College of Agriculture and Life Sciences, Univ. of Guam, UOG Station, Mangilao, Guam 96923.
Ambient photosynthetic photon flux during midday ranged from 950 to 1100 $\mu \mathrm{mol} \cdot \mathrm{m}^{-2} \cdot \mathrm{s}^{-1}$ at canopy height.

Twenty-six uniform plants were selected on 28 Nov. to study responses to seismic stress. Six plants were analyzed to determine the initial plant size (plant dry weight: 8.2 $\pm 0.5 \mathrm{~g}$ and leaf area: $847 \pm 81 \mathrm{~cm}^{2}$ ). Twenty plants with a mean initial height of $34.7 \pm 0.4 \mathrm{~cm}$ were spaced $35 \mathrm{~cm}$ apart as 10 single-plant replications of seismic and control treatments arranged in a completely randomized design. Seismic stress was administered for 10 set at 0900 and $1300 \mathrm{HR}$ each day by picking up each container and rocking it back and forth by hand two to three times per second, resulting in a 15- to $20-\mathrm{cm}$ displacement of plant tops. This process caused considerable leaflet flutter and contact with stems and other leaflets. The control plants remained untouched. The seismic treatment was continued for 40 days until 7 Jan. 1991. Temperature maxima ranged from 26 to $33 \mathrm{C}$ and minima from 12 to $24 \mathrm{C}$. Relative humidity maxima ranged from $87 \%$ to $94 \%$ and minima from $38 \%$ to $71 \%$, as recorded by a hygrothermograph (WEATHERtronics 5020, Qualimetrics, Sacramento, Calif.).

Final measurements included midday sto-

Table 1. Influence of 10-sec seismic stress administered twice daily from 29 Nov. 1990 to 7 Jan. 1991 (40 days) on the growth of carambola seedlings under glasshouse conditions, $\mathrm{n}=10$.

\begin{tabular}{lccc}
\hline \hline Variable & Control & $\begin{array}{c}\text { Seismic } \\
\text { stressed }\end{array}$ & $\begin{array}{c}\text { Percentage of } \\
\text { control }\end{array}$ \\
\hline Ht increase $(\mathrm{cm})$ & 43.5 & $16.9^{* * *}$ & 39 \\
Leaf area increase $\left(\mathrm{cm}^{2}\right)$ & 1055 & $627^{* * *}$ & 59 \\
TCA $\left(\mathrm{cm}^{2}\right)$ & 0.54 & $0.62^{*}$ & 115 \\
Plant dry wt $(\mathrm{g})$ & 25.9 & $23.4^{*}$ & 90 \\
RGR $^{\mathrm{y}}\left(\mathrm{mg}^{-1} \mathrm{~g}^{-1}\right.$ day & -1 \\
LAR $^{\mathbf{x}}\left(\mathrm{cm}^{2} \cdot \mathrm{g}^{-1}\right)$ & 28 & $25^{* *}$ & 89 \\
\hline
\end{tabular}

${ }^{2}$ Trunk cross-sectional area $2 \mathrm{~cm}$ from trunk base.

'Relative growth rate calculated from mean dry weights.

${ }^{x}$ Leaf-area ratio calculated from mean leaf area and whole plant dry weight.

$* * * * * * *$ Significant at $P=0.05,0.01$, or 0.001 , respectively. plant measurements and calculations were matal conductance (LI-1600; LI-COR, Lincoln, Neb.) of one fully expanded leaflet per plant, plant height, and trunk diameter $(2 \mathrm{~cm}$ above base of trunk). Leaves were removed and their total area measured (LI-3000 area meter, LI-COR). After the medium was washed from the roots, leaves, shoots, and roots were dried to constant weights at $60 \mathrm{C}$ in a forced-air oven. Variables calculated from the measured data included net assimilation rate (NAR), relative growth rate (RGR), and leaf-area ratio (LAR), according to Leopold and Kriedemann (1975), and trunk crosssectional area from measured trunk diameter. The data were subjected to analysis of variance.

Nineteen uniform plants were selected on 28 Nov. to study their responses to wind stress. Six plants were analyzed to determine initial plant size (plant dry weight: $5.3 \pm$ $0.5 \mathrm{~g}$ and leaf area: $613 \pm 93 \mathrm{~cm}^{2}$ ). Thirteen plants with a mean height of $26.4 \pm 0.5 \mathrm{~cm}$ were placed to receive an unidirectional wind load from two fans placed side by side on the greenhouse bench. The three plants most from the wind source received no wind, while the two plants closest to the wind source received $2.1 \mathrm{~m} \cdot \mathrm{s}^{-1}$ (at one-half canopy ant). The plants were arranged to obtain range of eight wind speeds between these for 51 mes. Continuous wind was applied collected as described for the seismic study. Stomatal conductance was recorded $» 1 \mathrm{~h}$ following termination of the wind load. All data were subjected to regression analysis with wind speed as the independent variable.

Two plants were chosen at random from among those remaining on $17 \mathrm{Feb} .1991$ to study the aftereffects of wind on net $\mathrm{CO}_{2}$ assimilation $(\mathrm{Pn})$. Measurements were made using a LI-6200 portable photosynthesis system with a LI-6250 gas analyzer and a 1liter chamber (LI-COR). One recently expanded, mature leaflet per plant was placed into the chamber fitted with inserts to allow $6 \mathrm{~cm}^{2}$ of exposed leaf surface. Three 10-sec $\mathrm{CO}_{2}$ depletion periods were recorded. Leaflets were clipped and discarded to assure use of a new leaflet during each subsequent measurement period, because gas exchange of this species is highly sensitive to repeated mechanical loading of leaf cuvettes (Marler and Mickelbart, 1992). This process was repeated $1 \mathrm{~h}$ later to give two measurements 


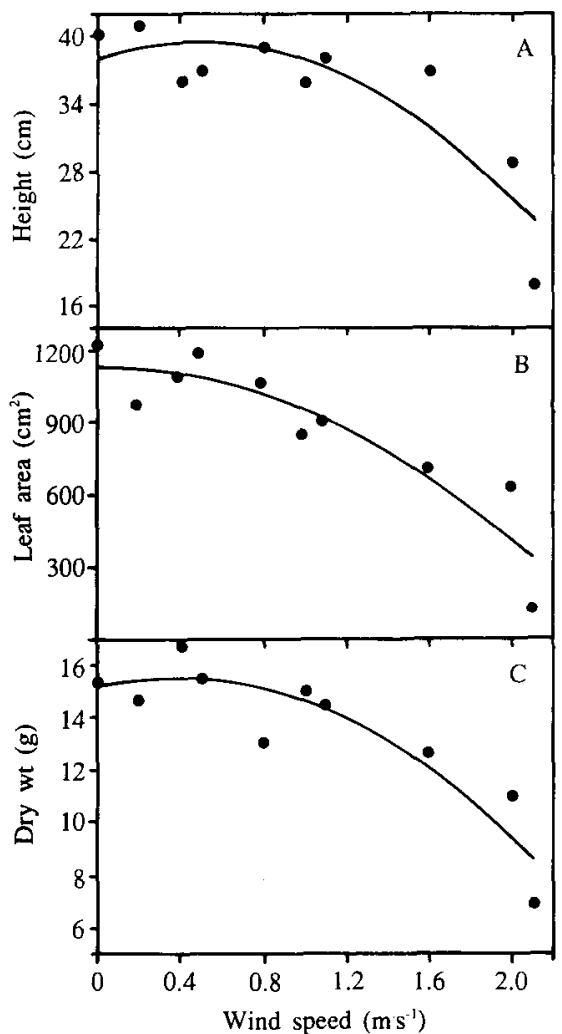

Fig. 1. Increase in plant height (A), leaf area (B), and dry weight (C) of carambola seedlings in response to 51 days of wind load under glasshouse conditions. Equations for response curves are: $\mathrm{y}=38.0+6.1 \mathrm{x}-6.2 \mathrm{x}^{2}, r^{2} 0.76(\mathbf{A})$; $\mathrm{y}=1133.0+9.3 \mathrm{x}-185.0 \mathrm{x}^{2}, r^{2}=0.84$ (B); $\mathrm{y}=15.2+1.8 \mathrm{x}-2.3 \mathrm{x}^{2} ; r^{2}=0.82$ (C).

before wind stress. One of the two plants was placed in a 30-min wind load of 2.2 $\mathrm{m} \cdot \mathrm{s}^{-1}$ on the morning of $18 \mathrm{Feb}$., then Pn was measured in the stressed and unstressed plants $30 \mathrm{~min}$ after termination of the wind stress and at hourly intervals up to $6 \mathrm{~h}$. Gas exchange also was measured two times the following day. This procedure was repeated with two other plants on $20 \mathrm{Feb}$. and on 4 and 6 Mar., for a total of four replications. Gas exchange before wind load was measured either the previous day as described or several hours before applying the wind load. Calculations of Pn were performed by the system software using standard equations.

Seismic stressed plants had a smaller mean whole plant dry weight, lower RGR and LAR, and a smaller mean height and leaf area than the unstressed ones (Table 1). Trunk crosssectional area increased in response to seismic stress, and there was a nonsignificant $9 \%$ depression of NAR by the seismic treatment (data not shown). Because reduced whole plant dry weight accompanied the increase in trunk diameter, we assume that a major shift in carbon allocation to trunk growth occurred due to shaking.

A rapid response of carambola leaflets to shaking also was observed. Leaflets moved from a horizontal to a vertical orientation following shaking, but returned to normal 1 to $2 \mathrm{~h}$ later. Rapid leaf movements resulting from shaking have been described as seis- monasty (Ball, 1969) and have long been known to occur in the Averrhea genus (Darwin, 1896) and specifically in carambola (Safford, 1905) in response to mechanical stimuli.

The response of plant growth to the range of wind loads tested in this study followed significant linear and quadratic trends, however, the fit to the quadratic trend was much higher for all growth variables. Typical response curves are shown for increases in height, leaf area, and dry weight (Fig. 1). Similar patterns were observed for trunk crosssectional area, NAR, RGR, and LAR. The increase in leaf area was the growth variable most severely and negatively affected by wind stress, with plants receiving $2.1 \mathrm{~m} \cdot \mathrm{s}^{-1} \mathrm{av}-$ eraging $11 \%$ that of control plants.

Plants and leaflets receiving seismic stress were similar in appearance to those receiving wind stress. Leaflets were smaller, darker green, and had irregular, broken margins.

The effect of 51 days of wind loading on stomatal conductance followed a response pattern similar to those in Fig. 1. Stomatal conductance of the plants in $2.1 \mathrm{~m} \cdot \mathrm{s}^{-1}$ wind was reduced to $44 \%$ of unstressed plants, from $233 \pm 20$ to $103 \pm 26 \mathrm{mmol} \mathrm{H}_{2} \mathrm{O} / \mathrm{m}^{2}$ per sec. Stomatal conductance of plants receiving seismic stress was $81 \%$ of conductance of unstressed plants. However, this was a nonsignificant response.

Net $\mathrm{CO}_{2}$ assimilation was reduced by wind within $30 \mathrm{~min}$ following stress (first poststress measurement), and no recovery was observed during the $6 \mathrm{~h}$ of measurement (data not shown). Wind-stressed plant Pn averaged $78 \%$ of control plant Pn throughout this period, with a mean of $5.75 \pm 0.39$ and $4.47 \pm 0.44 \mu \mathrm{mol} \mathrm{CO}_{2} / \mathrm{m}^{2}$ per sec for control and stressed plants, respectively. Complete recovery of Pn to the level of control plants occurred by the morning following the day of wind stress.

Altered leaf gas exchange in response to a range of mechanical stimuli has been reported for various species. Stomatal conductance, transpiration, photosynthesis, or respiration have been affected by wind (Grace, 1974; Grace and Thompson, 1973; Martin and Clements, 1935; Todd et al., 1972), rubbing or handling (Audus, 1935; Godwin, 1935; Mitchell et al., 1977), or shaking (Mitchell et al., 1977; Pappas and Mitchell, 1985).

Light intensity modifies plant responses to mechanical stimuli (Latimer, 1991). As a result, carambola responses to wind and seismic stresses under field conditions may not follow the same pattern as found under glasshouse conditionswith 50\% ambient light.

Temporary cessation of growth and a decline in general appearance of carambola trees occurs commonly in southern Florida following transplant from nurseries to windy field conditions during the spring. Some type of mechanical pretreatment may prove beneficial in conditioning carambola nursery trees before field planting.

Mechanical stress may be one means through which wind alters carambola growth and development, since morphological and growth responses to seismic and wind stresses were similar under the conditions of this study. Moreover, Jaffe (1980) suggests that wind is the most common environmental factor that results in touching-induced plant growth responses. Field-grown carambola trees are exposed to wind loads most days of the year, loads that generate mechanical stimulation longer than the short duration of seismic stress given daily in this study. Carambola growth responses to wind also may be regulated via reduced leaf gas exchange, as stomatal conductance and Pn were reduced following wind load under these conditions. There also is evidence, however, that hormonal (Biddington, 1986; Jaffe, 1980) and altered gene expression (Braam and Davis, 1990) are factors that may be involved with endogenous control of plant response to wind and mechanical stress.

\section{Literature Cited}

Audus, L.J. 1935. Mechanical stimulation and respiration rate in the cherry laurel. New Phytol. 34:386-402.

Ball, N.G. 1969. Nastic responses, p. 287. In: M.B. Wilkins (ed.). The physiology of plant growth and development. McGraw-Hill, New York.

Biddington, N.L. 1986. The effects of mechanically-induced stress in plants-a review. Plant Growth Renulat. 4:103-123.

Braam, J. and R.W. Davis. 1990. Rain-, wind-, and touch-induced expression of calmodulin and calmodulin-related genes in Arabidopsis. Cell 60:357-364.

Darwin, C. 1896. The power of movement in plants. Appleton, New York.

Godwin, H. 1935. The effect of handling on the respiration of cherry laurel leaves. New Phytol. 34:403-406.

Grace, J. 1974. The effect of wind on grasses I. cuticular and stomatal transpiration. J. Expt. Bot. 25:542-551.

Grace, J. 1977. Plant responses to wind. Academic, London.

Grace, J. and J.R. Thompson. 1973. The aftereffect of wind on the photosynthesis and transpiration of Festuca arundinacea. Physiol. Plant. 28:541-547.

Jaffe, M.J. 1980. Morphogenetic responses of plants to mechanical stimuli or stress. BioScience 30:239-243.

Latimer, J.G. 1991. Mechanical conditioning for control of growth and quality of vegetable transplants. HortScience 26:1456-1461.

Leopold, A.C. and P.E. Kriedemann. 1975. Plant growth and development. 2nd ed. McGraw-Hill, New York.

Marler, T.E. and M.V. Mickelbart. 1992. Repeated mechanical stress from leaf cuvette influences leaf gas exchange. HortScience 27:432434.

Martin, E.V. and F.E. Clements. 1935. Studies of the effect of artificial wind on growth and transpiration in Helianthus annuus. Plant Physiol. 10:613-636.

Mitchell, C.A., H.C. Dostal, and T.M. Seipel. 1977. Dry weight reduction in mechanicallydwarfed tomato plants. J. Amer. Soc. Hort. Sci. 102:605-608.

Neel, P.L. and R.W. Harris. 1971. Motion-induced inhibition of elongation and induction of dormancy in liquidambar. Science 173:58-59.

Pappas, T. and C.A. Mitchell. 1985. Influence of seismic stress on photosynthetic productivity, 
gas exchange, and leaf diffusive resistance of Glycine $\max$ (L.) Merril cv. Wells II. Plant Physiol. 79:285-289.
Safford, W.E. 1905. The useful plants of the island of Guam. Government Printing Office, Washington D.C.
Todd, G.W., D.L. Chadwick, and Sing-dao Tsai. 1972. Effect of wind on plant respiration. Physiol. Plant. 27:342-346.

\section{A Decision Support System for Apple Thinning in Colorado}

\author{
Matthew K. Rogoyski ${ }^{1}$ \\ Rogers Mesa Research Center, Department of Horticulture, Colorado \\ State University, 3060 Highway 92, Hotchkiss, CO 81419
}

\author{
A. Richard Renquist ${ }^{2}$ \\ Orchard Mesa Research Center, Department of Horticulture, Colorado \\ State University, 3168 B.5 Road, Grand Junction, CO 81503
}

Additional index words. crop load, artificial intelligence, Malus domestica

\begin{abstract}
A decision support system has been developed to help Colorado fruit growers with apple (Malus domestica Borkh.) thinning. This system can also be used as a teaching aid and as a tool for generating research hypotheses. The system determines if fruit thinning is needed by identifying catastrophic events that would eliminate the need for thinning. The major function of this decision support system is determination of tree responsiveness to chemical thinning agents. This is accomplished through analysis of the user's answers to questions related to the physiological status of the trees, environmental data, bearing history, and the apple variety in question. On the basis of the above analysis, two sets of recommendations are presented: general recommendations based on the variety selected, and specific ones for that variety based on growth stage and tree responsiveness to thinners. The user also is provided with the rationale for the recommendations.
\end{abstract}

Western Colorado apple growers are faced with complex decisions regarding crop load management. This intermountain area is prone to spring frosts and heat stress following bloom, with consequent difficulty in predicting the level of fruit set and potential problems with the return bloom. These factors make the decision process unique to this fruit-growing region. The decision support system described here is likely to simplify crop load management, but also may be useful as a teaching aid and hypothesis-generating tool.

There is a wealth of well-documented information about the benefits of apple thinning (Byers and Carbaugh, 1991; Edgerton and Williams, 1981; Looney, 1986; Williams, 1979). Decision support systems are becoming an integral part of the tools available to fruit producers as agriculture changes into an information-intensive endeavor (Crassweller et al., 1989; Plant et al., 1989). Because of the increasing complexity and number of production procedures, marketing questions, and government regulations, de-

Received for publication 23 Sept. 1991. Accepted for publication 20 Apr. 1992. Support by Colorado AFS projects 157 and 138. The cost of publishing this paper was defrayed in part by the payment of page charges. Under postal regulations, this paper therefore must be hereby marked advertisement solely to indicate this fact.

Assistant Professor.

${ }^{2}$ Associate Professor. cision support systems have become helpful tools when dealing with this quantity of information (McKinion and Lemmon, 1985; Naegele et al., 1987; Roach et al., 1987; Schmisseaur and Doluschitz, 1987).

Our decision support system for apple thinning is geared toward students of fruit growing and experienced fruit growers who want to explore or critically evaluate their thinning practices. This decision support system was developed as an "intelligent assistant" to help the users but not to replace experts (Feigenbaum, 1983; Winograd, 1987). The user of our system would be expected to take an active role in the interpretation of the recommendations presented by the system.

The original objective of this work was to develop a teaching aid and hypothesis-generating tool for apple-thinning methods. However, this system is intended to evolve into a management tool for apple growers of western Colorado.

\section{System}

The overall system consists of two programs: 1) the decision support system and 2 ) the program for creating and modifying the knowledge base. The latter program is not needed to use the decision support system. Both programs are written by M.K.R. in the $\mathrm{C}$ language. Their design and implementation are based on concepts and source code examples presented by Harbison and
Steele (1987), Schildt (1987), and Rolston (1988). The source code and related documentation are available upon request. The minimum requirements to run the system are: a computer using MS/PC-DOS (version 2.10 or higher), one floppy disk drive, $256 \mathrm{~K}$ RAM, and a printer.

The knowledge base for the decision support system is organized as a series of modules, implemented as files. Module 1 contains information about events that would eliminate the need for thinning. Module 2 contains the primary knowledge base that consists of factors that affect tree responsiveness to thinners. Module 3 contains a list of growth stages of apple trees pertinent to chemical thinning methods. Module 4 contains names of the varieties to be thinned. Two other groups of modules contain general recommendations and specific recommendations.

The overall flow path of the decisionmaking process and how information in var-

Table 1. Factors that influence tree thinning response.

Spur size

Spur age

Spur position

Shoot length

Condition of the foliage

Tree damage

Intentional trunk/scaffold scoring

Overall limb angle

Tree form

Growth habit

Tree physiological age

Density of flowers

Length of bloom period

Pollinators

Pollinizers

Flower fertilization

History of fruit set

Fruit set previous year

Expected fruit set

Fruit set pattern within cluster

Winter injury to buds

Winter injury to wood

Freeze after thinner application

Occurrence of recent light freeze

Postapplication weather

Weather before application of postbloom thinners

Drying conditions at the time of postbloom thinner use

Rewetting after application of postbloom thinners High temperatures after application of postbloom thinners

Prior application of blossom thinners

Fruit size variation within cluster

Table 2. Catastrophic events that rule-out a need for thinning.

Complete lack of bloom

Major winter injury to the tree

Major fire or herbicidal injury to the tree

Spring frost injury: Nearly all flowers killed throughout tree canopy. 